ROSA, R.R.P.A.

REF-ISSN1808-0804 Vol.XI (4),27-47, 2014.

\title{
FENILCETONÚRIA: UMA REVISÃO DE LITERATURA
}

\author{
PHENYLKETONURIA: A REVIEW OF LITERATURE
}

FENILCETONURIA: UNA REVISIÓN DE LA LITERATURA

\section{Ruy Roberto Porto Ascenso Rosa}

Faculdade Santo Agostinho, Avenida Valter Alencar n. 665 - São Pedro - Teresina - PI.

Email: ruyascenso23@hotmail.com

Submetido em 05/02/2014, Aceito em 21/11/2014

RESUMO: A Fenilcetonúria, causada pela deficiência da enzima fenilalanina hidroxilase é a causa mais frequente de deficiência intelectual e, desponta como a mais comum das doenças que envolvem erros congênitos. Foi descrita inicialmente pelo químico norueguês Asbjorn Fölling, em 1934, que, após seis meses de estudo, publicou seus achados denominando a doença recém descoberta como Imbecillitas Phenylpyruvi. Devido à possibilidade de realizar a detecção da falta da enzima logo ao nascer, realiza-se o diagnóstico através da Triagem Neonatal com o Teste do Pezinho. O tratamento conta com auxilio de uma equipe multidisciplinar e perdura por toda a vida. Tendo como objetivo analisar a Fenilcetonúria, desde a sua descoberta até os dias atuais, propôs-se esta pesquisa que, quanto à natureza, é uma pesquisa básica e, quanto aos procedimentos, é uma pesquisa bibliográfica. Utilizaram-se artigos publicados entre os anos 2009 a 2013, sobre o tema Fenilcetonúria nas principais bases de dados. Analisou-se o histórico da patologia, a etiologia desse erro inato do metabolismo, seus sintomas, formas de diagnóstico e tratamento. Constatou-se que embora haja bastante avanço na prevenção e tratamento, novas pesquisas são direcionadas na melhoria do tratamento, através da biotecnologia, para proporcionar maior qualidade de vida aos portadores. 


\title{
i) Revista Eletrônica de Farmácia
}

\author{
ROSA, R.R.P.A. \\ REF-ISSN1808-0804 Vol.XI (4),27-47, 2014.
}

PALAVRAS-CHAVE: Fenilcetonúrias. Triagem Neonatal. Fenilalanina Hidroxilase.

ABSTRACT: The Phenylketonuria, caused by deficiency of the enzyme phenylalanine hydroxylase and the most common cause of mental retardation, is emerging as the most common disease involving congenital errors. It was initially described in 1934 by Asbjorn Fölling, Norwegian chemical, which, after six months of study, published his findings styling the newfound disease as Imbecillitas Phenylpyruvi. Due to the possibility of performing fault detection of the enzyme at birth, is performed the diagnosis through neonatal screening with heel prick test. The treatment needs the aid of a multidisciplinary team and lasts for a lifetime. Having as objective to analyze the Phenylketonuria, since its discovery to the present day, it was proposed this research that, concerning the nature, is a basic research and that concerning of the procedures, is a literature review. Were used articles published between the years 2009 to 2013 on the subject Phenylketonuria in the databases. It was analyzed the history of pathology, the your etiology, its symptoms, the methods of diagnosis and of treatment. It was found that although there is enough progress in prevention and treatment, the new researches are directed, through biotechnology, into better treatments to provide better quality of life for patients.

KEYWORDS: Phenylketonurias. Neonatal Screening. Phenylalanine Hydroxylase.

RESUMEN: La fenilcetonuria, causada por la deficiencia de la enzima fenilalanina hidroxilasa y la causa más común de retraso mental, y surge como la enfermedade más común que implican errores innatos. Fue descrita inicialmente en 1934, por el químico noruego Asbjorn Fölling, después de seis meses de estudio, cuando publicó sus hallazgos dando el nombre esta enfermedad Imbecillitas Phenylpyruvi. Debido a la posibilidad de llevar a cabo la detección de fallos de la enzima al nacer, lleva a cabo el diagnóstico mediante el cribado neonatal. El tratamiento dura toda la vida. Este estudio tuvo como objetivo analizar la fenilcetonuria, desde su descubrimiento hasta nuestros días. Así comenzó la investigación, con respecto a la naturaleza es una investigación básica, con relación a los procedimientos es una investigación tipo revisión de la literatura. Se utiliza artículos publicados entre 2009 a 2013 sobre el tema en las principales bases de datos. Analizamos la historia de la patología, la etiología de este error innato del metabolismo, sus síntomas, y sus métodos de 
ROSA, R.R.P.A.

REF-ISSN1808-0804 Vol.XI (4),27-47, 2014.

diagnóstico y tratamiento. Se encontró que a pesar de que hay suficiente progreso en la prevención y el tratamiento, estudios buscan mejorar el tratamiento mediante la biotecnología.

PALABRAS CLAVES: Fenilcetonurias. Tamizaje Neonatal. Fenilalanina Hidroxilasa.

INTRODUÇÃO

A Fenilcetonúria (PKU, abreviatura do inglês pheylketonuria) é a mais comum das doenças que envolvem erros congênitos. A sua descoberta e descrição teve início em 1934 quando um jovem casal norueguês, Harry e Borgny Egeland, observaram que seus filhos ao nascerem aparentemente normais começaram a apresentar deficiência intelectual associada a um odor característico na urina. Ao ser procurado o químico norueguês Asbjorn Fölling iniciou uma série de testes na urina das crianças e ao adicionar cloreto férrico, que na presença de cetonas reage apresentando a coloração marromavermelhada, observou como resultado uma reação até então não descrita: o aparecimento de uma cor

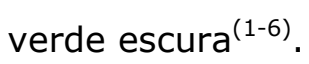

Logo após, o químico detectou que a excreção de ácido fenilpirúvico e fenilacetato eram os responsáveis pelo estranho odor da urina, seis meses depois publicou seus achados, denominando a doença recém descoberta como Imbecillitas Phenylpyruvi. Sendo descrita como um erro inato do metabolismo que acaba acumulando fenilalanina (Phe) e seus metabólitos tóxicos nos tecidos, especialmente no sistema nervoso central. E este foi o primeiro distúrbio metabólico hereditário associado à etiologia da deficiência intelectual $^{(1,6-9)}$.

A Phe, um aminoácido presente em quase todos os alimentos, que para a maioria das pessoas é um nutriente inofensivo, atua na constituição de proteínas e também como precursor de outras moléculas. Porém somente uma pequena parte é usada na síntese protéica e o excedente é convertido, necessitando do cofator tetraidrobiopterina ( $\mathrm{BH} 4)$, pela enzima hepática fenilalanina hidroxilase em tirosina, esta por sua vez, além de atuar na síntese protéica atua como precursora da melanina, neurotransmissores e os hormônios adrenalina e tiroxina ${ }^{(2,7,10)}$.

A falta da enzima é verificada assim que a pessoa nasce, pois as 
ROSA, R.R.P.A.

REF-ISSN1808-0804 Vol.XI (4),27-47, 2014.

anormalidades metabólicas começam a aparecer quando a criança inicia a ingestão de proteínas, neste caso através do leite, logo após ela passa a excretar a Phe, o ácido fenilpirúvico, o ácido fenilático e outros metabólitos na urina que passa a apresentar um odor fétido(4).

Estima-se que cerca de uma criança a cada 24.310 nascidas no Brasil é incapaz de produzir a enzima Fenilalanina Hidroxilase. Com a falta dessa enzima não é possível converter o excesso de Phe em tirosina e, esse indivíduo é então denominado fenilcetonúrico. O acúmulo excedente passa a ser convertido em ácido fenilpirúvico, este por sua vez inibe vias metabólicas responsáveis pela produção de certos lipídeos importantes na constituição da membrana de mielina, causando prejuízo no processo de mielinização, comprometendo gravemente 0 desenvolvimento neurológico. Embora cause graves consequências, a Phe não deve ser retirada totalmente da dieta dos fenilcetonúricos, pois é necessária em quantidades adequadas para 0 desenvolvimento nos parâmetros da normalidade ${ }^{(7,9-12)}$.

Atualmente a PKU é considerada parte de um espectro mais amplo das Hiperfenilalaninemias, que são condições em que há aumento de fenilalanina(3). Diante do exposto essa revisão tem 0 objetivo de analisar a situação da PKU desde a sua descoberta até o presente momento, analisando as melhoras já conquistadas e as que ainda poderão ser alcançadas, por meio de um estudo sistemático de artigos científicos sobre o tema escolhido.

\section{MÉTODO}

A metodologia aplicada a este estudo é a exaustão do tema estudado através de revisão bibliográfica, sendo realizada uma pesquisa com o termo Phenylketonuria nas principais Bases de Dados (Tabela 1). Foi escolhida essa metodologia porque as pesquisas bibliográficas são fundamentais em todas as áreas de estudo sendo responsável por levantar dados de uma questão e oferecer fundamentação teórica para um problema $^{(13-15)}$.

Os artigos identificados pela estratégia de busca inicial foram avaliados independentemente conforme 0 seguinte critério de inclusão: artigos descrevendo PKU ou outro tipo de hiperfenilalaninemia. Foram identificadas publicações nos 
ROSA, R.R.P.A.

REF-ISSN1808-0804 Vol.XI (4),27-47, 2014.

idiomas português, inglês e espanhol.

Essa busca ocorreu mediante pesquisa em Bases de Dados utilizando-se o termo Phenylketonuria, este termo foi utilizado devido a língua inglesa ser utilizada em praticamente todos os idiomas como a oficial para a segunda língua nos títulos, resumos e descritores; assim, teve-se um maior alcance na busca, a qual retornou artigos em outras línguas além da língua portuguesa. Em algumas Bases de língua portuguesa (Tabela 1), quando este termo não retornava resultados, utilizou-se a tradução do termo para a língua portuguesa (Fenilcetonúria) ou ainda outro termo relativo ao tema (Tabela 1 ). A etapa de busca inicial retornou 10.177 artigos distribuídos entre 2009 e 2013.

As etapas da seleção dos artigos, conforme Tabela 1, ocorreram da seguinte maneira: 1) inicialmente, artigos publicados no período de 01/01/2009 a 31/05/2013 sobre 0 tema delimitado; 2) artigos que reportassem algum resultado relevante ao estudo e não apenas uma citação sobre o tema; 3) arquivos disponíveis para acesso livre, salvo quando o autor conseguia com outros autores uma cópia do artigo completo. Resultando 32 artigos.

Tabela 1 - Seleção dos artigos utilizados na pesquisa.

\begin{tabular}{|c|c|c|c|c|c|c|c|c|}
\hline BUSCA & $\begin{array}{l}\text { RESULTADO } \\
\text { PARCIAL }\end{array}$ & \multicolumn{4}{|c|}{$\begin{array}{c}\text { ANO/ } \\
\text { QUANTIDADE }\end{array}$} & $\begin{array}{c}\text { PRIMEIRA ETAPA } \\
\text { DE SELEÇÃO }\end{array}$ & $\begin{array}{l}\text { SEGUNDA ETAPA } \\
\text { DE SELEÇÃOO }\end{array}$ & $\begin{array}{l}\text { RESULTAD } \\
\text { O FINAL }\end{array}$ \\
\hline \multicolumn{9}{|l|}{ SCIELO } \\
\hline $\begin{array}{c}\text { Pesquisa com o termo } \\
\text { Phenylketonuria, em todos os índices } \\
\text { no site: } \\
<\text { http://www.scielo.org/php/index.p } \\
\text { hp }>\text {. }\end{array}$ & 77 resultados. & $\begin{array}{l}1967 \\
(01) \\
1974 \\
(01) \\
1988 \\
(01) \\
1990 \\
(01) \\
1993 \\
(01) \\
\end{array}$ & $\begin{array}{l}1999 \\
(01) \\
2000 \\
(03) \\
2002 \\
(07) \\
2003 \\
(05) \\
2004 \\
(08) \\
\end{array}$ & $\begin{array}{l}2005 \\
(04) \\
2006 \\
(05) \\
2007 \\
(04) \\
2008 \\
(03) \\
2009 \\
(09) \\
\end{array}$ & $\begin{array}{l}2010 \\
(06) \\
2011 \\
(05) \\
2012 \\
(10) \\
2013 \\
(02)\end{array}$ & $\begin{array}{l}45 \text { artigos rejeitados } \\
\text { automaticamente } \\
\text { por não atenderem } \\
\text { ao critério de } \\
\text { inclusão referente ao } \\
\text { ano de publicação. } \\
\text { Restando } 32 \text { artigos. }\end{array}$ & $\begin{array}{l}21 \text { artigos rejeitados } \\
\text { por não reportarem } \\
\text { resultados de } \\
\text { interesse, conforme } \\
\text { os critérios de } \\
\text { inclusão deste } \\
\text { trabalho. }\end{array}$ & $\begin{array}{l}11 \text { artigos } \\
\text { selecionado } \\
\text { s por } \\
\text { atenderem } \\
\text { a todos os } \\
\text { critérios de } \\
\text { inclusão. }\end{array}$ \\
\hline \multicolumn{9}{|l|}{ PUBMED } \\
\hline $\begin{array}{c}\text { Pesquisa com o termo } \\
\text { Phenylketonuria no site: } \\
\text { <http://www.ncbi.nlm.nih.gov/pubm } \\
\text { ed }>\text {. }\end{array}$ & 6925 resultados. & $\begin{array}{c}1937 \\
(01) \\
1945 \\
(01) \\
1946 \\
(01) \\
1947 \\
(01) \\
1948 \\
(01) \\
1950 \\
(01) \\
1951 \\
(07) \\
1953 \\
(03) \\
1954 \\
(03) \\
1955 \\
(08) \\
1956 \\
(11) \\
1957 \\
(34) \\
1958 \\
(04) \\
1959 \\
(04) \\
1960 \\
(33) \\
1961 \\
(63) \\
1962 \\
(55) \\
\end{array}$ & $\begin{array}{c}1964(138) \\
1965(115) \\
1966(123) \\
1967(152) \\
1968(17) \\
1969(142) \\
1970(185) \\
1971(169) \\
1972(137) \\
1973(15) \\
1974(169) \\
1975(154) \\
1976(122) \\
1977(127) \\
1978(142) \\
1979(14) \\
1980(119)\end{array}$ & $\begin{array}{c}1981(111) \\
1982(133) \\
1983(118) \\
1984(105) \\
1985(114) \\
1986(107) \\
1987(116) \\
1988(12) \\
1989(111) \\
1990(135) \\
1991(123) \\
1992(12) \\
1993(138) \\
1994(151) \\
1995(102) \\
1996(137) \\
1997(92)\end{array}$ & $\begin{array}{c}1998(127) \\
1999(129) \\
2000(161) \\
2001(113) \\
2002(132) \\
2003(15) \\
2004(119) \\
2005(126) \\
2006(01) \\
2007(12) \\
2008(125) \\
2009(13) \\
2010(139) \\
2011(141) \\
2012(136) \\
2013(102) \\
2014(02)\end{array}$ & $\begin{array}{c}6392 \text { artigos } \\
\text { rejeitados } \\
\text { automaticamente } \\
\text { por não atenderem } \\
\text { ao critério de } \\
\text { inclusão referente ao } \\
\text { ano de publicação. } \\
\text { Restando } 533 \\
\text { artigos. }\end{array}$ & $\begin{array}{c}531 \text { artigos } \\
\text { rejeitados devido a } \\
\text { impossibilidade de } \\
\text { acesso ao texto } \\
\text { completo; sendo que } \\
\text { destes 213, } \\
\text { analisados mediante } \\
\text { resumo disponível, } \\
\text { não reportavam } \\
\text { resultados de } \\
\text { interesse ao estudo } \\
\text { conforme os critérios } \\
\text { de inclusão. }\end{array}$ & $\begin{array}{c}\text { Devido às } \\
\text { limitações } \\
\text { frente ao } \\
\text { acesso ao } \\
\text { texto } \\
\text { completo } \\
\text { foram } \\
\text { selecionado } \\
\mathrm{s} \text { apenas } 02 \\
\text { artigos } \\
\text { desta base } \\
\text { de dados. }\end{array}$ \\
\hline
\end{tabular}




\section{- Revista Eletrônica de Farmácia}

ROSA, R.R.P.A.

REF-ISSN1808-0804 Vol.XI (4),27-47, 2014.

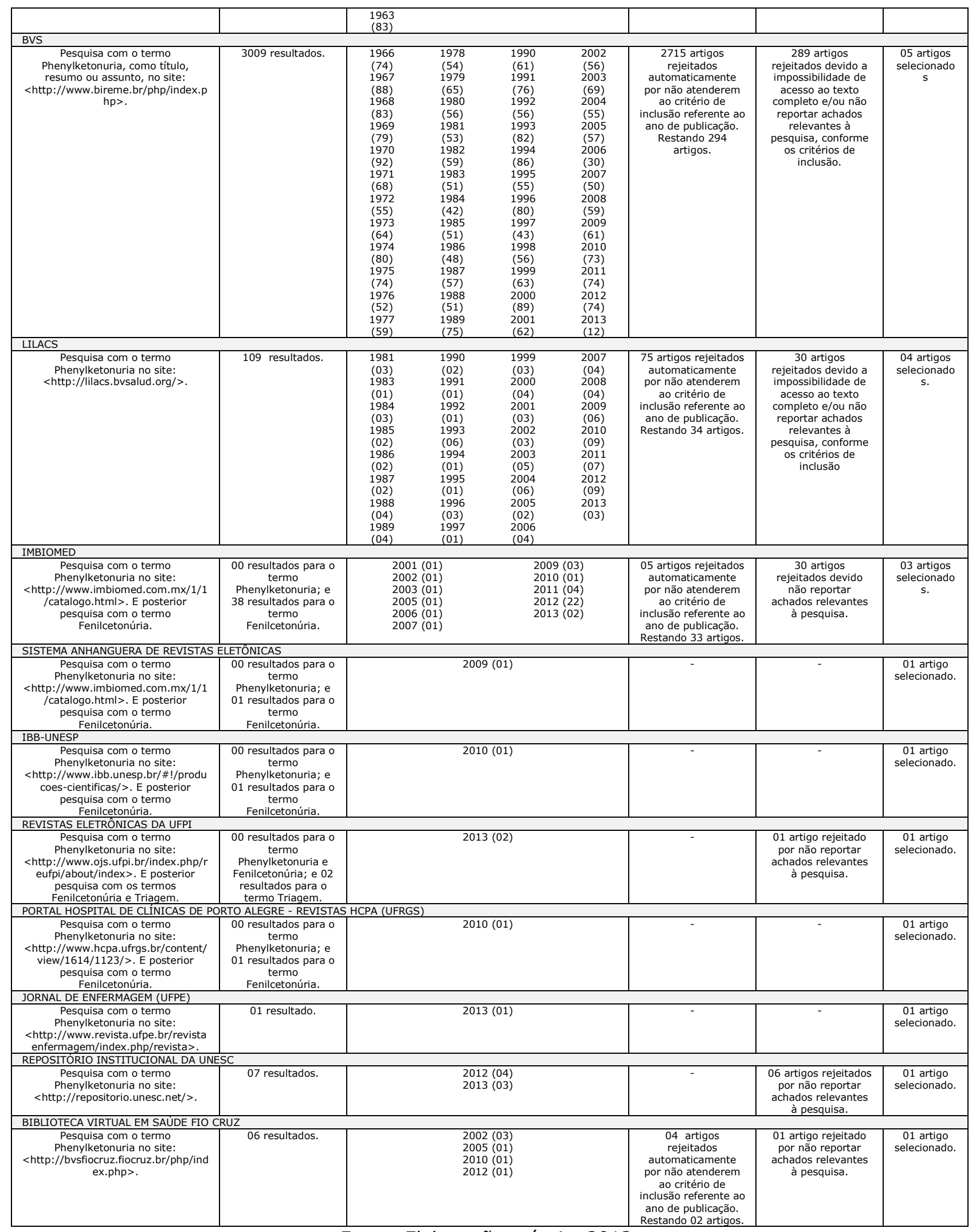

Fonte: Elaboração própria, 2013. 
ROSA, R.R.P.A.

REF-ISSN1808-0804 Vol.XI (4),27-47, 2014.

A última etapa para definir os artigos utilizados compreendeu 0 processo de busca cruzada, onde se realizou a impressão dos 32 artigos, agrupando-os por ano, para poder visualizar os que estavam repetidos e excluí-los, conforme Figura 1. Assim, foi incluído na presente revisão um total de vinte e três artigos, além de três livros, uma portaria específica e uma dissertação os quais serviram como suporte

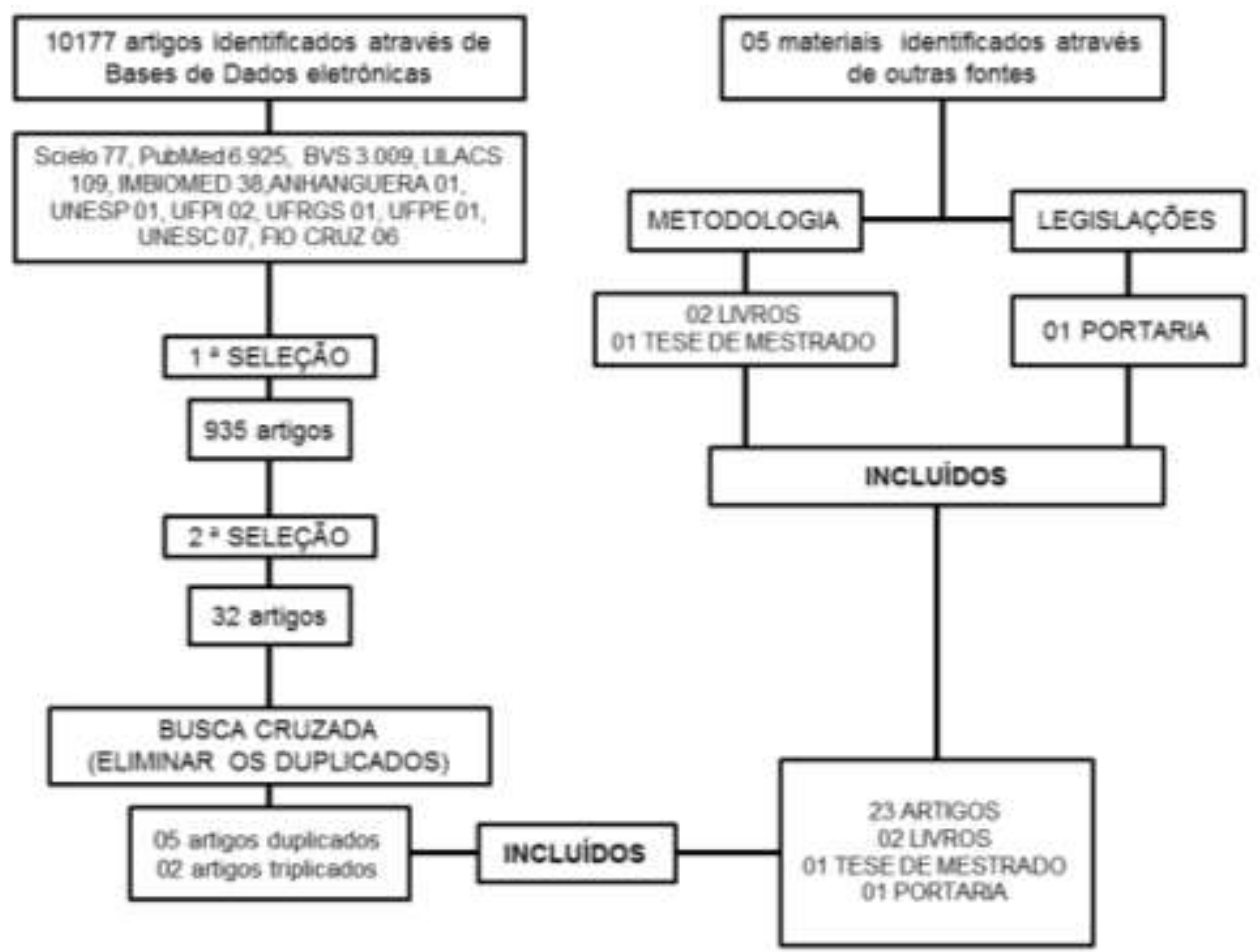

Figura 1 - Percurso metodológico adotado no estudo.

Fonte: Elaboração própria, 2013.

\section{DESENVOLVIMENTO}

Conforme Gráfico 1, as publicações sobre o tema PKU, dada a sua grande importância, vem crescendo bastante nos últimos anos. Verifica-se que o ano de 2012 desponta como o que mais teve publicações e que o ano de 2013 tem perspectiva de manter essa projeção ultrapassando os últimos resultados. 
ROSA, R.R.P.A.

REF-ISSN1808-0804 Vol.XI (4),27-47, 2014.

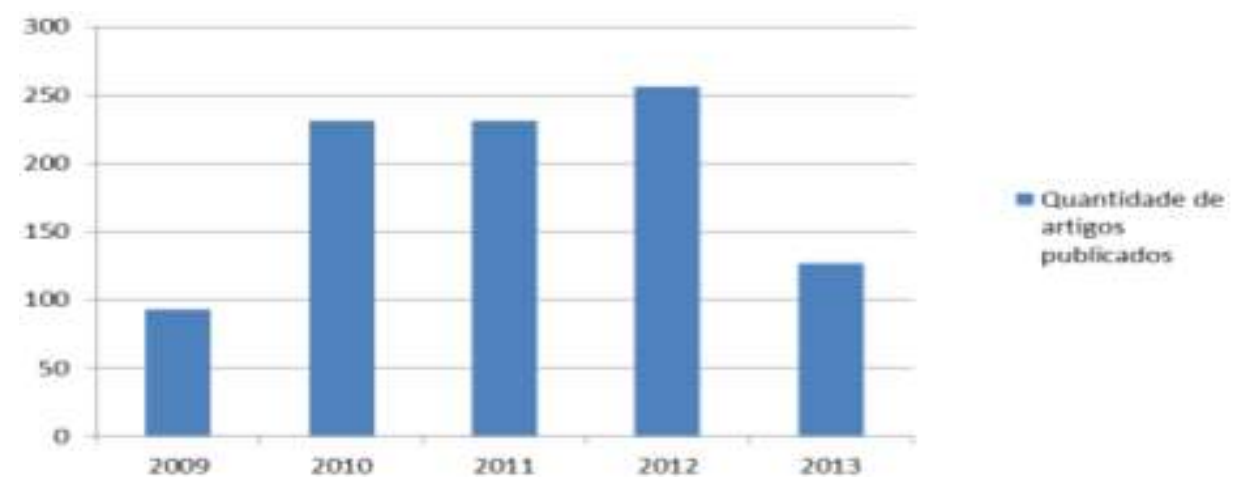

Gráfico I - Quantidade de artigos sobre Fenilcetonúria publicados por ano no período de janeiro de 2009 a julho de 2013.

Fonte: Elaboração própria, a partir de dados disponíveis nas Bases de Dados, 2013.

Frente a esses dados, reportamse neste tópico os principais resultados dos artigos analisados e os avanços sobre o tema que os mesmos trazem, através de uma análise descritiva.

\section{EPIDEMIOLOGIA}

DA

\section{FENILCETONÚRIA}

A PKU é o mais comum dos erros inatos do metabolismo em todo o mundo, apesar de ser a patologia triada no Programa Nacional de Triagem Neonatal (PNTN) que apresenta a menor incidência descrita. Uma pesquisa realizada na Argentina pela Fundación de Endocrinología Infantil, que teve seu início em 1985 e é realizada até hoje com 1,3 milhões de crianças, mostra que em todas as suas formas clínicas, a PKU mostrou uma incidência de aproximadamente $1: 12.000$ recémnascidos por ano ${ }^{(6,16)}$.

A prevalência da PKU varia muito em torno do mundo. Na Europa a prevalência é 1:10.000 nascidos vivos, mas em algumas áreas desse continente supera esse valor. Nos Estados Unidos da América, a prevalência é 1:15.000. Na América Latina varia de 1:50.000 a 1:25.000, sendo que geralmente a prevalência é mais elevada no sul dessa região. $\mathrm{Na}$ Ásia varia cerca de 1:15.000 para 1:100.500 em regiões da China, 1:200.000 na Tailândia e 1:70.000 no Japão. E a África parece ter uma 


\section{i) Revista Eletrônica de Farmácia}

ROSA, R.R.P.A.

REF-ISSN1808-0804 Vol.XI (4),27-47, 2014.

prevalência muito baixa de $\mathrm{PKU}$, aproximadamente $1: 100.00^{(5,7)}$.

A PKU ocorre em todos os grupos étnicos e sua incidência anual em recém-nascidos no Brasil pode variar de 1:2.600 até 1:26.000, devido a grande variabilidade genética. $\mathrm{E}$ a sua prevalência anual no país é estimada em 1:24.780 habitantes $^{(8,17)}$.

\section{CAUSAS DA FENILCETONÚRIA}

A PKU é considerada como um erro metabólico e a causa mais frequente de deficiência intelectual, e está especificamente relacionada com - metabolismo do aminoácido essencial Phe. De herança autossômica recessiva, com um índice de recorrência de 25\%, causa alteração no gene da enzima Fenilalanina Hidroxilase hepática na região q22-q-24.1 localizado no cromossomo 12, sendo que já foram descritas mais de 500 mutações nas regiões codificadoras desse cromossomo ${ }^{(1-2,4,9-12,17-22)}$.

Essa alteração impede a síntese da enzima hepática, responsável pela conversão do aminoácido Phe em tirosina, variando entre a completa ausência de atividade e 5\% de atividade residual, o que ocasiona altas concentrações de Phe no plasma em concentrações normais. Essa elevação ocasiona a passagem desse aminoácido em quantidade excessiva para o sistema nervoso central, sendo que este acúmulo possui efeito tóxico ocasionando prejuízo cerebral difuso irreversível ${ }^{(2,4,9,11-12,20-22)}$.

Podem também ocorrer casos menos frequentes de hiperfenilalaninemia causados pela má formação do tetraidrobiopterina (BH4), um co-fator enzimático que desempenha importante função para a hidroxilação da Phe, o que origina uma PKU maligna ou atípica com um quadro neurológico mais grave ${ }^{(10)}$.

\section{ASPECTOS BIOQUÍMICOS}

Os aspectos bioquímicos da hidroxilação da Phe em humanos compreende uma reação complexa envolvendo pelo menos seis enzimas diferentes e seus cofatores, conforme observado esquematicamente na Figura 2. A reação central, a oxidação da L-fenilalanina, que é um aminoácido essencial não sintetizado pelo organismo, para L-tirosina, um aminoácido não essencial, é catalisada pela fenilalanina hidroxilase (fenilalanina 4-mono-oxigenase; $\mathrm{PAH}$; EC 1.14.16.1). Sendo que esta é a 
ROSA, R.R.P.A.

REF-ISSN1808-0804 Vol.XI (4),27-47, 2014.

principal via de catabolização da Phe $75 \% \quad$ da ingerida e a responsável por cerca de aminoácido ${ }^{(5-6)}$.

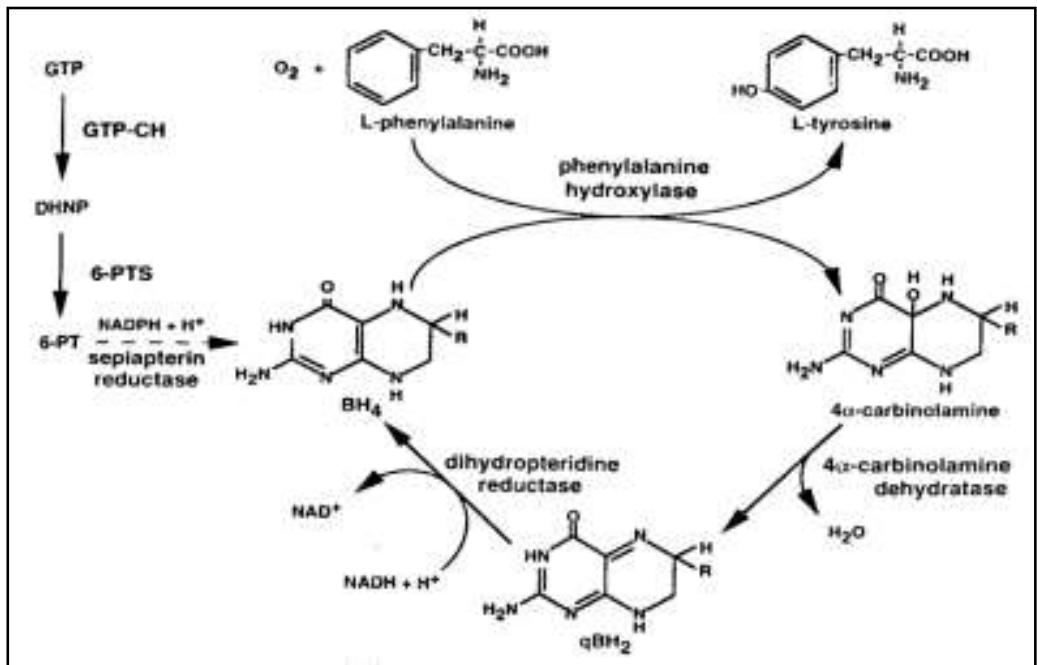

Figura 2 - Sistema de hidroxilação da fenilalanina em humanos Fonte: Scriver ${ }^{(23)}$.

São requisitos básicos para que ocorra a reação de hidroxilação a presença da Phe, oxigênio, Lfenilalanina e do cofator BH4. Para que ocorra a regeneração do cofator BH4, são necessários di-idropteridina redutase (DHPR), nucleotídeo piridina reduzido e 4a-carbinolamina desidratase. E para sua síntese participam a GTP-CH (guanosina trifosfato cicloidrolase) e 6-PTPS (6pirovoil-tetraidropterina sintetase) ${ }^{(6)}$.

\section{CONSEQUÊNCIAS}

Ao nascer o lactente parece normal, porque recebeu por via placentária os aminoácidos necessários, não interferindo, assim, no desenvolvimento do sistema nervoso, pois este tem maturação máxima somente após o nascimento. Se a enfermidade não for diagnosticada e tratada imediatamente após o nascimento, ocorre o comprometimento da saúde com o aparecimento de sintomas neurológicos, como por exemplo, as crises de convulsão, as quais geralmente ocorrem entre os seis e 18 meses de vida. Consequentemente mais de $99 \%$ das crianças que as apresentam PKU tornam-se deficientes mentais de grau e 
ROSA, R.R.P.A.

REF-ISSN1808-0804 Vol.XI (4),27-47, 2014.

intensidade variáveis (de moderado a agudo) e sempre irreversível ${ }^{(2,4-6,8-}$ 10,12).

Após o diagnóstico de PKU, mesmo havendo a possibilidade de amamentação quando associada a um rigoroso controle, a suspensão do aleitamento materno é recomendada devido à dificuldade, durante a mamada, de quantificar a ingestão de Phe, ocorrendo variações nos níveis sanguíneos acima dos recomendados. Porém, confrontando essa orientação existem os sentimentos desenvolvidos pela mãe quando tem que parar abruptamente de amamentar seu filho, pois desenvolvem sentimentos de culpa e tristeza por causa da interferência na relação com seu bebê, além da aceitação do diagnóstico ${ }^{(11)}$.

As crianças que apresentam essa patologia e não são tratadas em tempo adequado, possuem tendência a apresentar comprometimento progressivo das funções cerebrais, com o desenvolvimento de diversos sintomas como: deficiência intelectual, que é a sequela mais importante dessa patologia; tremor; microcefalia; hiperatividade; crises convulsivas; atraso global do desenvolvimento; déficit de atenção; e, até mesmo, comportamentos autísticos $^{(2,5,7-9,11-12,21)}$.

Além dos sintomas citados acima são descritos também: alterações no crescimento, sendo este reduzido; odor característico na urina; e falta de pigmentação, devido à inibição completa da hidroxilação da tirosina pela tirosinase, que é a primeira etapa na formação da melanina. A síntese reduzida desse pigmento na PKU clássica confere tonalidades mais claras aos cabelos, pele e íris. Os portadores possuem, também, expectativa de vida reduzida, podendo metade morrer por volta dos 20 anos e três quartos por volta dos $30^{(5,8-9,17)}$.

\section{CLASSIFICAÇÕES DA} FENILCETONÚRIA

A PKU se apresenta em diferentes tipos de apresentação metabólica, formando um grupo heterogêneo de doenças, sendo reconhecidas e classificadas de acordo com o percentual de atividade enzimática encontrada, em: PKU clássica, PKU leve e hiperfenilalaninemia não PKU. A atividade enzimática é encontrada através de uma estimativa após realizar dosagem dos níveis de Phe 
ROSA, R.R.P.A.

REF-ISSN1808-0804 Vol.XI (4),27-47, 2014.

sérica, fornecendo assim uma estimativa da atividade enzimática residual, que depende, em parte, da mutação presente no gene da enzima hepática fenilalanina hidroxilase, o que permite a definição do fenótipo bioquímico ${ }^{(1,5,9,24)}$.

Na PKU Clássica a atividade da enzima Fenilalanina Hidroxilase é inferior a $1 \%$, sendo praticamente inexistente. Nesta situação os pacientes apresentam níveis plasmáticos de Phe ao diagnóstico em concentrações superiores a $20 \mathrm{mg} / \mathrm{dL}$ e uma tolerância a esse aminoácido inferior a 350 mg/dia. A PKU Leve tem atividade enzimática de 1 a $3 \%$ e os níveis de Phe encontram-se entre 10 e $20 \mathrm{mg} / \mathrm{dL}$, com tolerância a Phe mais elevada que na PKU clássica na Hiperfenilalninemia Transitória ou Permanente a atividade enzimática encontra-se superior a 3\%, sendo esta situação considerada benigna sem apresentação de qualquer sintomatologia clínica, e os níveis de Phe encontram-se entre 4 e 10 $\mathrm{mg} / \mathrm{dL}^{(1,9,17,24)}$.

Outro fenótipo possível com incidência de 1 a 3\%, denominado PKU Atípica, acontece devido uma deficiência na biossíntese ou regeneração do cofator da enzima fenilalanina hidroxilase, a $\mathrm{BH} 4$. Nesses casos não há mutações no gene da enzima. Essa deficiência de $\mathrm{BH} 4$ é responsável por um fenótipo neurológico grave, pois o portador não responde, na maioria dos casos, ao tratamento dietético padrão ${ }^{(1,24)}$.

\section{DIAGNÓSTICO}

Na década de 50 foram iniciados estudos de triagem por meio da adição de cloreto férrico à fralda dos bebês recentemente molhada, sendo conhecido como Teste da Fralda. Porém, as alterações detectáveis na urina só surgem em fases posteriores às que são detectáveis no sangue e, muitas vezes, já com os primeiros sinais de lesão no sistema nervoso. Como a excreção do ácido fenilpirúvico é demorada, o teste só podia ser realizado com resultados confiáveis após algumas semanas de vida, reduzindo assim a cobertura deste teste e retardando o início do tratamento. Posteriormente, foram desenvolvidos novos métodos de diagnóstico ${ }^{(6,24)}$.

As bases para a detecção precoce e tratamento da PKU, que existem atualmente, foram lançadas por três conclusões principais: 1) na década de 1930, Asbjorn Fölling identificou níveis elevados de Phe no 
ROSA, R.R.P.A.

REF-ISSN1808-0804 Vol.XI (4),27-47, 2014.

sangue (hiperfenilalninemia) como a causa dos déficits neuropsicológicos; 2) na década de 1950, Horst Bickel introduziu uma dieta pobre em Phe para tratar a PKU; e 3) na década de 1960, Robert Guthrie introduziu um teste de diagnóstico adequado para rastreamento em massa de hiperfenilalninemia conhecido como Teste do Pezinho(7).

Nos dias atuais, muitos países ao redor do mundo incluem um teste para hiperfenilalaninemia em PNTN, que vão de métodos simples até sistemas mais modernos baseados em espectrometria de massa. No Brasil a PKU é diagnosticada por meio do "Teste do Pezinho" (TP), cuja obrigatoriedade, para todo o território brasileiro, consta no Estatuto da Criança e do Adolescente ${ }^{(5,7,12,25)}$.

\subsection{TRIAGEM NEONATAL}

A TN que teve início na década de 1950 no Reino Unido, e somente em 1960 iniciou em outros países. Seu objetivo é a detecção precoce dos erros inatos do metabolismo e outras patologias assintomáticas no período neonatal e, faz parte dos cuidados de saúde materno-infantil. É centrada na detecção de Hipotireoidismo Congênito $(\mathrm{CH}$, do inglês Congenital
Hypothyroidism) e PKU, a fim de evitar ou reduzir o retardo do desenvolvimento intelectual e físico em crianças $^{(8,10,22,25-27)}$.

Todos os recém-nascidos devem ser submetidos ao teste, pois sendo diagnosticada, antes da manifestação clara de seus sintomas, a maioria das doenças podem ser tratadas com sucesso. Isso é confirmado pelo fato de que uma pessoa com PKU iniciando o tratamento logo após o nascimento consegue impedir a maioria das complicações neuropsicológicas. Por utilizar amostras de sangue coletadas do calcanhar, o exame ficou popularmente conhecido como TP e, é capaz de detectar a PKU, O HC, a fibrose cística, doenças falciformes e outras hemoglobinopatias $(1,5,7,10,22,26)$.

$\mathrm{Na}$ América Latina três países foram pioneiros na implementação do programa de TN da PKU a nível nacional e alcançando uma cobertura superior a 98\%. Cuba em 1986, Costa Rica em 1990 e o Chile em $1992^{(28)}$.

No Brasil, assim como ocorre em outros países em desenvolvimento, a implementação da TN ocorreu de forma desorganizada e sem estrutura. Tendo início em 1976 em São Paulo, quando foi implantado a TN para PKU, a primeira doença triada no país. Este foi um dos primeiros estados a 
ROSA, R.R.P.A.

REF-ISSN1808-0804 Vol.XI (4),27-47, 2014.

formular a Lei Estadual no 3.914/1983, seguido pelo estado do Paraná que formulou a Lei Estadual no $867 / 1987^{(1,3-4,25,29)}$.

A primeira legislação, a nível federal, que se tem conhecimento referente à TN no país foi publicada no Rio de Janeiro em 1985, a qual tornava obrigatória a TN para o $\mathrm{HC}$ e para a PKU. O que ocasionou, a partir de iniciativas individuais, a implantação em diferentes Estados sem apresentar relação uns com os outros. Somente em 1992 foi complementada a Legislação Federal definindo em âmbito nacional as patologias a serem triadas ${ }^{(4)}$.

Apesar de todas essas iniciativas a TN só adquiriu condição de programa de saúde pública em 2001 com a criação do PNTN através da portaria no 822/2001 do Ministério da Saúde, alcançando uma cobertura de $82 \%$. O programa está organizado em três fases de implantação, com os seguintes testes realizados: Fase I (HC e PKU), Fase II (HC, PKU e hemoglobinopatias) e Fase III (HC, PKU, hemoglobinopatias e fibrose cística). Por fim, o PNTN estabeleceu em todos os Estados brasileiros os Serviços de Referência em Triagem Neonatal (TN) tendo como metas, além da cobertura universal, a garantia de realização de todas as etapas, ou seja, desde a coleta até o tratamento e o acompanhamento dos casos confirmados $(1,6,26,28)$.

Atualmente quase todos os países realizam a TN para PKU com uma frequência variável. A incidência entre os afrodescendentes nos EUA, por exemplo, é de 1:50.000, ao passo que a incidência de PKU em caucasoides é estimada em 1:10.000; percebe-se aqui que a cobertura da TN para PKU ainda é baixa se compararmos com o número de casos que ocorrem ${ }^{(6)}$.

No Brasil, mais especificamente no Estado do Piauí, além do agravante citado no paragrafo anterior sobre a baixa taxa de realização da $\mathrm{TN}$, verifica-se também o atraso no início desse teste no Estado, pois somente no final de 2004 foi que o Ministério da Saúde o habilitou no Programa Estadual de Triagem Neonatal ao credenciar o Hospital Infantil Lucídio Portela com serviço de referência em TN. Nesta época ele foi habilitado a fazer apenas a triagem de Fase I e somente em 2005 é que passou a realizar o teste gratuitamente através do Sistema Único de Saúde(26).

\subsubsection{PROCEDIMENTOS PARA REALIZAÇÃO DO TESTE}


ROSA, R.R.P.A.

REF-ISSN1808-0804 Vol.XI (4),27-47, 2014.

O TP consiste na coleta de algumas gotas de sangue no calcanhar do recém-nascido e por lei todos os hospitais e Unidades Básicas de Saúde têm a obrigação de realizar a coleta e encaminhar para o laboratório. A família tem a obrigação de exigir o teste, além de confirmar a sua realização. Nos últimos 20 anos, o sistema de TN formou seus próprios padrões para controle de qualidade na coleta de amostras e procedimentos laboratoriais $^{(4,26-27)}$.

A coleta de sangue é feita entre 72 horas e 7 dias após o nascimento em crianças adequadamente alimentadas. Se for adiada por algum motivo, deve ser feita dentro de 20 dias, após o nascimento. O preparo da amostra consiste na utilização do sangue, 0 qual permeia para impregnar o papel filtro mantendo um tamanho similar, com pelo menos 8 mm de diâmetro, colocando a amostra na parte da frente ou no lado de trás do papel sem contaminação. 0 material deve ser enviado para o laboratório de triagem no prazo de 5 $\operatorname{dias}^{(8,10,22,26-27,29)}$.

Amostras de sangue extras devem ser armazenados por pelo menos 5 anos em $2^{0}-8^{\circ} \mathrm{C}$ para uma possível reanálise. Todos os laboratórios de triagem devem processar e analisar as amostras de sangue no prazo de 5 dias úteis após o recebimento e relatar casos positivos imediatamente.

laboratório deve realizar um retorno mensal às unidades responsáveis pela coleta de amostras de sangue, referente aos resultados da triagem $^{(27)}$.

Quando a dosagem de Phe no sangue encontra-se maior ou igual a $240 \mu \mathrm{mol} / \mathrm{L}$ a criança é encaminhada para diagnóstico diferencial e, quando necessário, tratamento essencialmente dietético. Pois, quando não tratado ou quando não se consegue manter os níveis de Phe entre $>2 \mathrm{mg} / \mathrm{dL}$ e $<6 \mathrm{mg} / \mathrm{dL}$, os portadores tendem a apresentar os sintomas da patologia ${ }^{(8,11,29)}$.

\section{TRATAMENTO}

Após diagnosticada a PKU, inicia-se 0 tratamento preferencialmente até os primeiros 21 dias de vida, o qual é essencialmente paliativo e perdura por toda a vida. Assim, o recém-nascido será submetido a uma dieta com teor controlado de Phe a fim de reduzir os níveis plasmáticos para uma concentração próxima à normalidade. 
ROSA, R.R.P.A.

REF-ISSN1808-0804 Vol.XI (4),27-47, 2014.

O aleitamento materno também deverá ser suspenso ou reduzido, dependendo do caso. Essas medidas buscam evitar as manifestações clínicas e bioquímicas da doença ${ }^{(4-5,9-}$ $12,19,25)$.

A dieta tem por base uma fórmula láctea comercial de concentração conhecida de aminoácidos, inclusive a Phe, com a quantidade determinada pelos níveis sanguíneos de Phe e/ou pela atividade da enzima hepática fenilalaninahidroxilase, variando em cada indivíduo de acordo com a tolerância à ingestão deste aminoácido. Essa fórmula tem a finalidade de manter as concentrações sanguíneas do aminoácido dentro dos limites adequados para a faixa etária ${ }^{(8,10-}$ 12,18).

As concentrações de Phe no sangue consideradas de referência para fenilcetonúricos são: de 120 a $360 \mu \mathrm{mol} / \mathrm{L}$ para lactentes e préescolares, até $480 \mu \mathrm{mol} / \mathrm{L}$ para escolares e até $700 \mu \mathrm{mol} / \mathrm{L}$ para adolescentes. O tratamento deve ser mantido por toda a vida, e qualquer descuido em relação à ingestão de Phe pode ocasionar déficits na função neuropsicológica e no processo de mielinização do sistema nervoso. Todavia, os níveis plasmáticos ideais de Phe ainda são questionados ${ }^{(5,8-9,11-}$ 12).

\subsection{MANEJO DIETOTERÁPICO}

Desde a década de 1950 são conhecidas estratégias para o manejo dietoterápico da doença, sendo grande o desafio de se iniciar o tratamento no período présintomático. $\mathrm{O}$ esquema de administração da dieta é individualizado e calculado de acordo com as necessidades específicas, pois a tolerância à Phe varia de acordo com a idade, peso e grau da deficiência enzimática. O cálculo inicial baseia-se na quantidade de proteínas necessárias para a faixa etária. Usualmente a dieta deve conter entre 250 e 500 mg de FAL/dia, quando o normal de ingestão para um paciente não portador de PKU é de $2.500 \mathrm{mg}$ de $\mathrm{FAL} / \mathrm{dia}(1,24)$.

A dieta constitui um fator de complicação devido à lista de restrições ser extensa e englobar alimentos comuns do cotidiano como arroz, feijão, ovos, diversas frutas, todos os tipos de carne, soja e derivados do leite. A suplementação é então realizada com os Medical Foods ou com fórmulas metabólicas, sendo tolerável para o fenilcetonúricos a 
ROSA, R.R.P.A.

REF-ISSN1808-0804 Vol.XI (4),27-47, 2014.

ingestão máxima de $20 \mathrm{mg}$ de Phe a cada $100 \mathrm{~g}$ da alimentação(10).

\subsection{ACOMPANHAMENTO}

O termo adesão é caracterizado como uma medida do comportamento de uma pessoa correspondente com as recomendações de um profissional da saúde, que vai desde seguir uma dieta, tomar um medicamento até mesmo mudar seu estilo de vida. Apesar de não haver medida padrão para estabelecer a adesão, estima-se que as taxas de não adesão aos diversos tratamentos terapêuticos sejam altas. A adesão à dieta é influenciada por fatores cognitivos, emocionais, fisiológicos e culturais além, da capacidade e disposição em seguir a dieta que variam entre os pacientes e cuidadores. Após essas considerações ressalta-se aqui que é imprescindível a adesão ao tratamento por parte dos portadores de PKU, pois este proporciona melhoria na qualidade de vida além, de evitar os sintomas provenientes dessa doença aos pacientes, cujo tratamento é iniciado logo ao nascer e mantido por toda a vida(9-10,17-19,24,29).

$$
\text { o acompanhamento e }
$$
elaboração da dieta dos pacientes portadores de PKU são feitos por uma equipe multidisciplinar logo após o diagnóstico. Além disso, deve ser feito - acompanhamento clínico e laboratorial com análise quantitativa de Phe, no mínimo mensalmente até o primeiro ano de vida, para que a mãe seja esclarecida sobre a dieta e os riscos das transgressões para 0 desenvolvimento de seu filho. E somente após este período, o acompanhamento passa a ser bimestral ou trimestral dependendo da evolução da criança e das dificuldades da família. Algumas situações especiais de dificuldade no seguimento do tratamento podem definir uma rotina diferenciada de acompanhamento clínico e/ou laboratorial, com a redução dos prazos acima definidos ${ }^{(24)}$.

\subsection{NOVOS TRATAMENTOS}

É discutida atualmente a possibilidade de tratamentos alternativos para a PKU por meio de terapia gênica ou até mesmo pela reposição enzimática. Contudo, a realidade mais próxima dos pacientes ainda consiste em restaurar os níveis normais de Phe no sangue com a restrição dietética a alimentos ricos em Phe ${ }^{(10)}$. 
ROSA, R.R.P.A.

REF-ISSN1808-0804 Vol.XI (4),27-47, 2014.

\section{CONSIDERAÇÕES FINAIS}

Percebeu-se através da literatura consultada que as pesquisas que abordaram a PKU foram importantes no estabelecimento de programas de detecção precoce e melhores formas de tratamento. Em vários países existe uma boa cobertura dos recém-nascidos através da TN, oferecendo a estes melhores condições de vida através do diagnóstico precoce de erros metabólicos. Mesmo com todo o avanço já demonstrado espera-se ainda encontrar, através da biotecnologia, melhores formas de tratamento. No entanto, a realidade mais próxima é a manutenção dos níveis de Phe através de restrições dietéticas. Espera-se que, daqui a alguns anos, possam ser desenvolvidos novos meios de tratamento da PKU proporcionando ainda mais qualidade de vida aos portadores dessa doença.

\section{REFERÊNCIAS}

1. Amorim T, Boa-Sorte N, Leite MEQ, Acosta AX. Aspectos clínicos e demográficos da fenilcetonúria no Estado da Bahia. Rev Paul Pediatr. 2011. 29(4):612-7.

2. Cuevas RD, Arrimes JC, Babastro GC, LuwandaI LB, Borrero LD. Metabolismo de compuestos nitrogenados. MEDISAN. 2012. 16(6):978-1004.

3. Karam SM, Jardim LB, Giugliani R, Horta BL. Triagem neonatal para hiperfenilalaninemia: um estudo de coorte. Revista da AMRIGS, Porto Alegre, 2012. 56(1):17-21.

4. Reis JC, Vasconcelos PS, Santos RM. Enfrentamento dos pais no acompanhamento dos filhos portadores de fenilcetonúria. Anuário da Produção Acadêmica Docente. 2009. 3(4):7-22.

5. Santos RM. Efeito genotóxico da fenilalanina: implicações para a fenilcetonúria. [Tese]. Criciúma: Programa de Pós-Graduação em Ciências da Saúde, Universidade do Extremo Sul Catarinense. 2012. 
ROSA, R.R.P.A.

REF-ISSN1808-0804 Vol.XI (4),27-47, 2014.

6. Sorte TRSAB. Estudo das bases moleculares da fenilcetonúria no nordeste do Brasil. [Tese]. Salvador: Programa de Pós-graduação em Biotecnologia e Saúde e Medicina Investigativa, Fundação Osvaldo Cruz. 2010.

7. Blau N, Spronsen FJ, Levy HL. Phenylketonuria. Lancet. 2010. 376:1417-27.

8. Mancini PC, Starling ALP, Penna LM, Ramos CAV, Ferreira MIO, Iório MCM. Achados audiológicos em crianças com fenilcetonúria. Rev Soc Bras Fonoaudiol.2010. 15(3):383-9.

9. Mancini PC, Starling ALP, Alves CFT, Martins TMM, Iório MCM. Alterações auditivas e fenilcetonúria: uma revisão sistemática. Rev CEFAC. 2010. 12(1):140-5.

10. Gonçalves VSS, Ferreira TRAS, Valadares BLB. Fenilcetonúria: abordagem reflexiva e transdiciplinar no programa de genética para cursos de nutrição. Rev Simblio-Logias. 2010. 3(5):144-51.

11. Lamônica DAC, Stump MV, Pedro KP, Rolim-Liporacci MC, Caldeira ACGC, Anastácio-Pessan FL, Gejão MG. Acompanhamento do aleitamento materno no tratamento de crianças com fenilcetonúria. J Soc Bras Fonoaudiol. 2012. 24(4):3816-9.

12. Ribeiro PS, Torres TL, Starling ALP, Iório MCM, Mancini PC. Crianças com fenilcetonúria: avaliação audiológica básica e supressão das otoemissões. Rev Soc Bras Fonoaudiol. 2012. 17(3):248-53.

13. Gil AC. Como elaborar projetos de pesquisa. 5th. ed. São Paulo: Atlas. 2010.

14. Lakatos EM, Marconi MA. Metodologia Científica. 6th. ed. São Paulo: Atlas. 2011.

15. Rodrigues TKA. Caracterização de MPEs brasileiras quanto ao conhecimento de ferramentas de gestão. [Tese]. Lavras: Universidade Federal de Lavras. UFLA. 2012. 
ROSA, R.R.P.A.

REF-ISSN1808-0804 Vol.XI (4),27-47, 2014.

16. Chiesa A, Fraga C, Prieto L, Pardo ML. Modelo de atención de pacientes com fenilcetonuria (PKU) em Argentina. Acta Pediatr Mex. 2012. 33(6):308-10.

17. Nalin T, Perry IDS, Refosco LF, Netto CBO, Souza CFM, Vieira TA, Picon PD, Schwartz IVD. Fenilcetonúria no sistema único de saúde: avaliação de adesão ao tratamento em um centro de atendimento do Rio Grande do Sul. Rev HCPA. 2010. $30(3): 225-32$.

18. Castro IPS, Borges JM, Chagas HA, Tibúrcio J, Starling ALP, Aguiar MJB. Relationships between phenylalanine levels, intelligence and socioeconomic status of patients with phenylketonuria. J Pediatr [online], Rio de Janeiro, 2012. 88(4):353-6.

19. Giugliani L, Sitta A, Vargas CR, Silva LCS, Nalin T, Pereira MLS, Giugliani R, Schwartz IVD. Tetrahydrobiopterin responsiveness of patients with phenylalanine hydroxylase deficiency. J Pediatr [online], Rio de Janeiro, 2011. 87(3):245-51.

20. Lopes FM, Brito KW, Pedatella FM, Santos EP, Silvestre HL, Araújo DL, Fernandes KF. Levantamento epidemiológico da fenilcetonúria no Estado de Goiás. Ensaios e Ciência: Ciências Biológicas, Agrárias e da Saúde. 2010. 14(2):61-70.

21. Silva GK, Lamônica DAC. Desempenho de crianças com fenilcetonúria no Teste de Screening de Desenvolvimento Denver - II. Pró-Fono Revista de Atualização Científica. 2010. 22(1):345-50.

22. Stranieri I, Takano OA. Avaliação do serviço de referência em triagem neonatal para hipotireoidismo congênito e fenilcetonúria no Estado de Mato Grosso, Brasil. Arq Bras Endocrinol Metab. 2009. 53(4):446-52.

23. Scriver CR, Kaufman S. Hyperphenylalaninemia: phenylalanine hydroxylase deficiency. In: Scriver $C R$, et al. The metabolic and molecular bases of inherited disease. New York: McGraw-Hill. 2001. p.1667-724. 


\section{(i) Revista Eletrônica de Farmácia}

ROSA, R.R.P.A.

REF-ISSN1808-0804 Vol.XI (4),27-47, 2014.

24. Ministério da Saúde. Portaria no 847 de 06 de novembro de 2002 [Internet]. Brasília (Brasil): Ministério da Saúde; 2002 [cited 2013 Jun 11]. Available from: http://dtr2001.saude.gov.br/sas/PORTARIAS/PORT2002/PT-847.htm.

25. Costa SN, Boa-Sorte N, Couto RD, Oliveira EG, Couto FD. Triagem neonatal para fenilcetonúria, hipotireoidismo congênito e hemoglobinopatias no recôncavo baiano: avaliação da cobertura em Cruz das Almas e Valença, Bahia, Brasil. Revista Baiana de Saúde Pública. 2012. 36(1):831-43.

26. Santos LRO, Rocha SS, Gouvéia MTO, Oliveira FBM, Araujo AKL, Rodrigues IS. Teste do pezinho: avaliação de desempenho de um programa de triagem neonatal. Rev enferm UFPE [online], Recife, 2013. 7(1):773-8.

27. Zhan JY, Qin YF, Zhao ZY. Neonatal screening for congenital hypothyroidism and phenylketonuria in China. World J Pediatr. 2009. 5(2):136-9.

28. Borrajo GJC. Panorama epidemiológico de la fenilcetonúria (PKU) en Latinoamérica. Acta Pediatr Mex. 2012. 33(6):279-87.

29. Leal YR, Neta MHMP, Rocha SS. Triagem neonatal: conhecimentos e contribuições da equipe de enfermagem. Rev Enferm UFPI. 2013. 2(1):16-21. 